\title{
Study on the Mechanical Cumulative Damage Model of Slope Fault Fracture Zone under the Cumulative Effect of Blasting Vibration
}

\author{
Tingyao Wu', Zhou Chuanbo*1, Jiang Nan¹, Xia Yuqing ${ }^{1}$, Bin Zhu \\ ${ }^{1}$ Department of Civil engineering, Faculty of Engineering, China University of Geosciences, Wuhan 430074, China \\ * Corresponding author, e-mail: cbzhou@cug.edu.cn
}

Received: 26 March 2020, Accepted: 19 May 2020, Published online: 12 June 2020

\begin{abstract}
As for the slope with fault fracture zone, the fault fracture zone is the main sliding surface, whose shear strength parameter is the main calculation parameter of landslide occurrence. In this paper, shaking table model tests and damage theory were used to study the change of shear strength and mechanical cumulative damage model of fault fracture zone under the blasting vibration cyclic load. At first, the slope of Daye Iron Mine is selected as a case to study the shear strength weakening law of fault fracture zone by the similarity theory and the principle of the orthogonal test, in which the influence of the characteristics of vibration loading on the shear strength parameters of fault fracture zone with different thicknesses was studied. Secondly, by the assumption of Lemaitre strain equivalence and according to the extreme value characteristics of the normal stress-shear stress curve, the damage theory model of the fault fracture zone was reconstructed, and the microelement of fault was selected for analysis and divided into two parts, including damaged and undamaged materials. Finally, the results of the shaking table model tests were compared with the results of the shear cumulative damage model to verify the rationality of the theoretical model. Moreover, the predicted results of the theoretical model can better reflect the degradation trend of the fault fracture zone with the loading amplitude, normal stress, and loading times. It can be used as a reference for slope stability prediction under the action of cumulative static and dynamic loads.
\end{abstract}

Keywords

blasting vibration, cyclic load, fault fracture zone, cumulative damage model

\section{Introduction}

Landslides and earthquakes and volcanoes are the three major geological disasters in nature, which can lead to heavy casualties and huge economic losses [1-3]. It is well known that during an earthquake, the introduction of a coseismic force results in the instability of slopes, while during a rainfall event, the decrease in the shear strength of the soil layers and the addition of hydrological forces are the main reasons for the initiation of slope instability [4-5]. At the same time, the decrease of shear strength and the increase of pore water pressure are the main causes of landslide occurrence [6-7]. For the pore water pressure variation, there are many studies enabled researchers to deepen understanding of the initiation of many landslides, such as the possible reduction of pumping in unsaturated soil layers [8-9], the increase of pore water pressure due to the increase of the groundwater table [10], and the hydrological force accompanying the underground water flow [11-12].
For the shear strength reduction, earthquakes and repeated blasting vibration are the two main triggering factors for the shear strength reduction of the landslides. Therefore, numerous efforts had been made to examine the possible addition of a coseismic force to the slope [13-14], there are also many types of researches to investigate the initiation mechanisms of coseismic force-induced landslides [15]. One of the most important factors that can control the stability of high and steep slope is discontinuities. The key to managing the destructive effect of discontinuities is the knowledge of the discontinuities' shear mechanism, which is strongly affected by the joint roughness and the loading conditions [16]. Most of the constitutive models developed for monotonic loading conditions are not suitable for taking into account the effect of the cyclic loading conditions on predicting the shear behavior of rock joints [17]. Although the aforementioned studies have provided some 
insight into shear strength parameters of rock joints under pre-peak cyclic loading conditions, the shear mechanism and the discrepancy between increasing and decreasing of the shear strength by cyclic loading are not fully understood. Meanwhile, with the development of the large-scale engineering construction projects, a large number of ore mining and rock excavation projects continue to emerge. During the excavation of mining production, blasting, as a fast and crucial excavation method for hard rock mass, has been widely used. The instability problems of slopes with the fault zone have been affected by blasting vibration repeated again and again. Since repeated blasting vibration will produce the cumulative effect, which will cause cumulative damage to the shear mechanical properties of the fault zone of the slope subject to blasting vibration. At the same time, Koo et al. [19] only quantitatively evaluated several driving parameters of slope instability through field measured data and numerical simulation and did not address the problem of cumulative shear damage model of fault zone [18-19]. In reality, in the process of mining production and excavation, the location of explosion source was relatively concentrated, if the location of each blasting excavation and the distance between the blasting source and the fault zone were relatively constant, the solution of complex problem about the cumulative shear damage model of the fault zone, mentioned above, can be solved by simply studying the influence of different blasting vibration amplitude and blasting vibration times on the shear mechanism of the slope fault zone.

In this paper, combined with the similar theory of model test and shaking table tests, the actual project was selected as a case to study the shear strength weakening the law of fault fracture zone (Section 1). Next, the changes of cohesion force and internal friction angle of fault fracture zone with loading amplitude and loading time were analyzed, and the cumulative damage model of fault was obtained through the shaking table tests data, and the shear strength parameters of faults were studied with the change of fault thickness, and the influence of fault thickness on shear strength parameters under different loading times was obtained (Section 2). Thirdly, with the assumption of Lemaitre strain equivalence, the microelement of fault was selected for analysis and divided into two parts, including damaged and undamaged materials, and then by assuming that the microelement strength of fault material obeyed Weibull distribution and considering the influence of damage threshold, the cumulative damage evolution model of fault material was established to study the shear damage mechanism of fault fracture zone under blasting vibration (Section 3). Finally, the degradation constitutive model of shear strength of fault materials with the change of loading times and loading amplitude was compared with the shaking table tests data to verify the rationality of the theoretical model (Section 4).

\section{Engineering background}

\subsection{Design of test system}

In this paper, analyzing and evaluating the effect of the mining blasting on the slope was the main purpose of this paper. The fault zone of the slope ran across the entire slope, which was the key to the slope stability. Because the open pits and underground pits were so large that it was impossible and unnecessary to perform indoor simulation of the entire actual slope. Therefore, shaking table tests were carried out in the form of the model test based on similarity theory. In the study, the stress of the model along the direction of the fault was unchanged, so the model was simplified to a plane strain model. In order to meet the limitation of the bearing capacity of the laboratory shaking table, and conveniently test the fault cohesion and friction angle, the blasting vibration simulation tests were carried out in the form of a test block. Table 1 listed the parameters of the similarity coefficients of the key physical quantities in model test.

When the shear deformation occurred slowly or rapidly along the slide zone, the shear strength of sliding zone soil will decrease gradually after increasing to the peak value. At the same time, the sliding zone soil will finally reach a stable shear strength, which was the residual strength of the sliding zone soil. As the core component of the landslide, the strength characteristics of slip

Table 1 Similarity coefficients of key physical quantities in model test

\begin{tabular}{lcc}
\hline Physical quantity & Similarity & $\begin{array}{c}\text { Similarity coefficient } \\
\text { (* control quantity) }\end{array}$ \\
\hline Density $\rho$ & $C_{\rho}$ & $1.29^{*}$ \\
Elastic modulus $E$ & $C_{E}$ & 129 \\
Poisson ratio $\mu$ & $C_{\mu}$ & 1 \\
Cohesion $C$ & $C_{C}=C_{E} C_{\varepsilon}$ & 129 \\
internal friction angle $\varphi$ & $C_{\varphi}$ & 1 \\
Stress $\sigma$ & $C_{C}=C_{E} C_{\varepsilon}$ & 1 \\
Length $L$ & $C_{L}$ & $100^{*}$ \\
Time $T$ & $C_{T}$ & $10^{*}$ \\
Frequency $f$ & $C_{f}=C_{T}-1$ & 0.1 \\
Velocity $v$ & $C_{v}=C_{L} C_{T}-1$ & 10 \\
Acceleration $g$ & $C_{g}=C_{L} C_{T}-2$ & 1 \\
\hline
\end{tabular}


zone soil controlled the stability and deformation process of the landslide, which meant that the peak strength and residual strength were both important parameters in the calculation and evaluation of landslide stability. A large number of studies showed that the peak strength changed into residual strength in the process of large displacement shear failure of sliding soil. However, the shear strength characteristics of slip zone soil will change with the evolution of its physical properties and the change of the external environment, which had obvious dynamic characteristics [20-21]. Therefore, based on the similarity coefficients given in Table 1 and the paper of Jiang et al. [18], a large number of conventional physical and mechanical properties tests were carried out such as compressive strength, elastic modulus, shear strength, etc. And then the values of the physical and mechanical parameters of the fracture zone material were obtained. Meanwhile, in this paper, the residual shear strength of fault fracture zone was also an important factor in the research of cumulative damage model of shear strength of fault fracture zone, so the peak shear strength and residual shear strength of bedrock and fault fracture zone in the model test were both calculated by the similar ratio in Table 1, and obtained through a large number of orthogonal shear tests, which can meet the requirement of the similar ratio of peak shear strength and residual shear strength. The physical and mechanical parameters of the in-situ rock mass and the physical model were listed in Table 2. The similar materials for surrounding rock included gypsum, coarse sand, medium sand, iron concentrate, sodium citrate, water, and the ratio of their
Table 2 Physical and mechanical parameters of the in-situ rock mass and the physical model

\begin{tabular}{lcccc}
\hline & \multicolumn{2}{c}{ Surrounding rock } & \multicolumn{2}{c}{ The fault zone } \\
Type & $\begin{array}{c}\text { In-situ } \\
\text { rock } \\
\text { mass }\end{array}$ & $\begin{array}{c}\text { Similar } \\
\text { material }\end{array}$ & $\begin{array}{c}\text { In-situ } \\
\text { rock } \\
\text { mass }\end{array}$ & $\begin{array}{c}\text { Similar } \\
\text { material }\end{array}$ \\
\hline Density $/ \mathrm{g} \cdot \mathrm{cm}-3$ & 2.71 & 2.10 & 1.77 & 1.37 \\
Elastic modulus $/ \mathrm{GPa}$ & 20.70 & 0.16 & 2.45 & 0.02 \\
Poisson ratio & 0.23 & 0.23 & 0.20 & 0.20 \\
Peak cohesion $/ \mathrm{KPa}$ & 466 & 3.61 & 222 & 1.72 \\
Residual cohesion $/ \mathrm{KPa}$ & 380 & 3.16 & 180 & 1.40 \\
Friction angle $/{ }^{\circ}$ & 29.00 & 29.00 & 24.34 & 24.34 \\
Residual friction angle $/{ }^{\circ}$ & 26 & 26 & 23 & 23 \\
\hline
\end{tabular}

quality was $0.21: 0.33: 0.05: 0.42: 0.01: 0.16$, the fault similar materials for the fracture zone included barite powder, coarse sand, medium sand, silt, water, and the ratio of their quality was $0.74: 0.21: 0.05: 0.01: 0.14$.

\subsection{General information of the open pit slopes}

Daye Iron Mine is located in Tieshan District, Huangshi City, Hubei Province, PR China about $90 \mathrm{~km}$ west to Wuhan City, $25 \mathrm{~km}$ east to the downtown of Huangshi City and $15 \mathrm{~km}$ southeast to Daye City. Fig. 1 showed the location of Daye Iron Mine. It can be seen from Fig. 1 that throughout more than 100 years of mining activities, a deep open-pit mine with a longitudinal length of 2,400 meters and a horizontal direction of 1,000 meters has been formed, which demonstrated that the east open pit of Daye Iron Mine was selected as the study area.

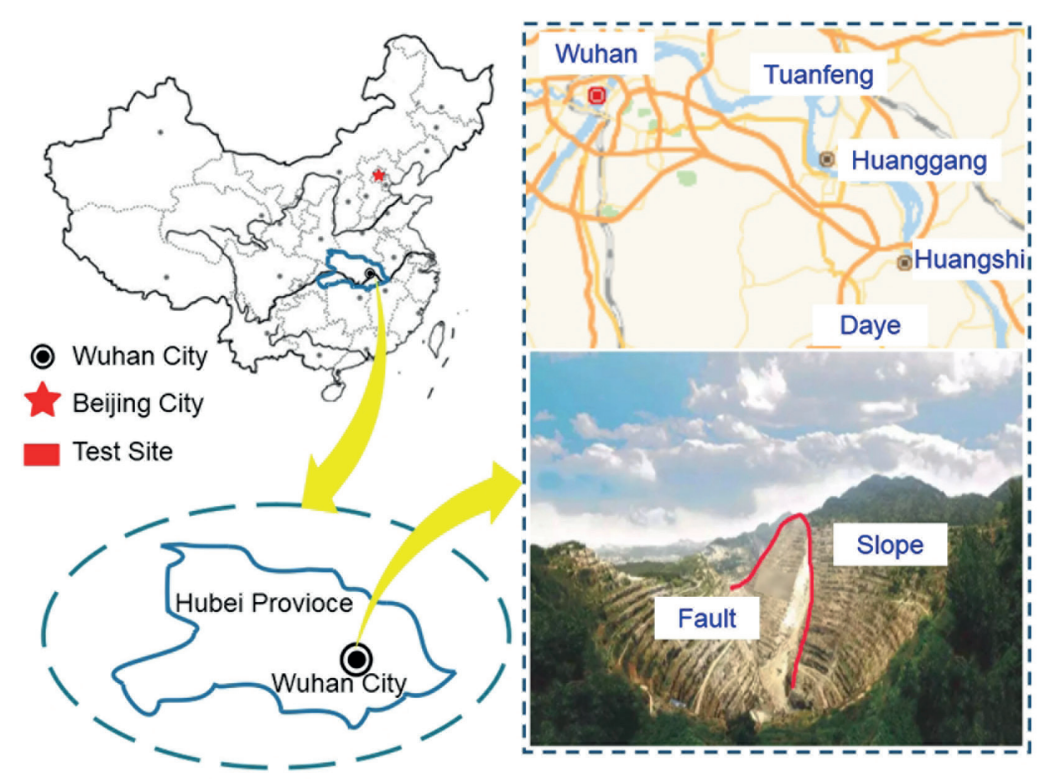

Fig. 1 Location of Daye Iron Mine 


\subsection{Design of test models}

The size of the test block was $15 \mathrm{~cm} \times 15 \mathrm{~cm} \times 15 \mathrm{~cm}$, and the thickness of the fault was $3 \mathrm{~cm}$. The schematic diagram of the frame structure of the test model was presented in Fig. 2. The schematic diagram of the three-dimensional structure of the model was given in Fig. 3.
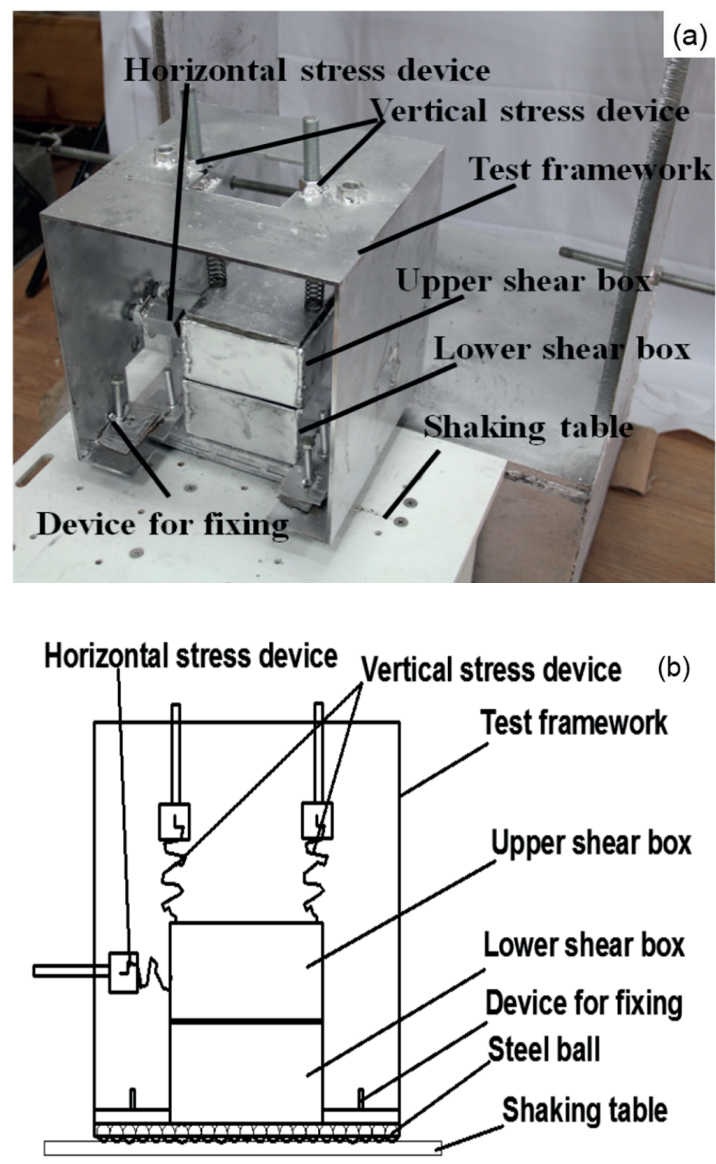

Fig. 2 Schematic diagram of the experimental model frame structure, (a) physical structure, (b) CAD structure

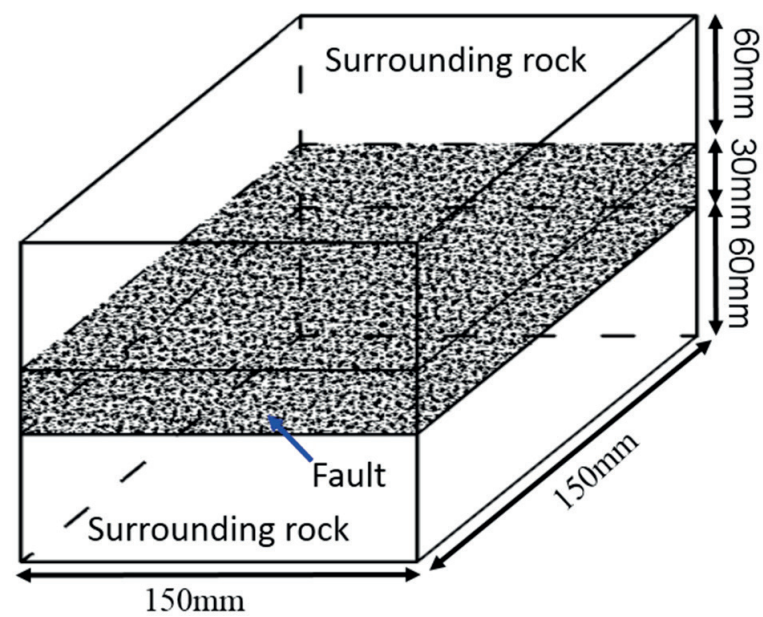

Fig. 3 Structure of the model

\subsection{Loading scheme for model experiments}

The seismic wave generated by the blasting is a random wave. If the original waveform of the blasting seismic wave is input to the shaking table for simulation of blasting vibration, it is most suitable. However, due to the difficulty in changing the frequency and amplitude, the sine waves were mostly used in the test. The reason was that sine waves have most of the characteristics of seismic waves, and they also have the advantage of simplifying calculations [22]. Meanwhile, since the characteristics of the wave include amplitude, wavelength, frequency. First of all, in terms of wave amplitude, the core of this paper was to study the influence of blasting vibration with different vibration amplitude and vibration times on the shear strength of fault fracture zone of the slope. According to the principle of a single variable, the amplitude of sine wave or seismic wave produced by blasting can be adjusted to the specified amplitude by instrument, at the same time, the amplitude of the vibration wave determined in the test was based on the field monitoring data, and which can be set accurately according to the requirements of the test, so as to ensure that under the same blasting vibration loading times, the influence of the loading amplitude of the blasting vibration wave generated by multiple different blasting on the shear strength of the fault fracture zone can be studied. Secondly, in terms of wavelength and frequency, according to the field monitoring results of vibration velocity of the fault in Daye Iron Mine and references [18, 23], the main frequency distribution range of the blasting seismic wave of Daye Iron Mine was $50-60 \mathrm{~Hz}$, the blasting vibration intensity distribution range was $0.5 \mathrm{~cm} / \mathrm{s}-2.2 \mathrm{~cm} / \mathrm{s}$, and the acceleration converted to the shaking table was $1.6 \mathrm{~m} / \mathrm{s}^{2}-7 \mathrm{~m} / \mathrm{s}^{2}$. At the same time, according to the field monitoring results, it is not difficult to find that the duration of the amplitude change of the seismic wave generated by blasting near the fault fracture zone from the rising stage and falling to nearly zero was generally $20 \mathrm{~ms}$ [23-24]. In the model test of this paper, the input sine wave was a half cycle sine wave, and its frequency was set to $50 \mathrm{~Hz}$, that is to say, the period of each vibration wave was $20 \mathrm{~ms}$, so it was reasonable to replace the blasting vibration by the halfsine wave in this paper. What's more, the main research in this paper was the influence of multiple blasting vibration on the mechanical properties of the fault fracture zone. Therefore, in the test, the seismic wave generated by blasting vibration was simplified as a half cycle sine wave as the loading of a blasting vibration wave, which can not 
only solve the problem that the monitored seismic wave was difficult to input to the equipment, but also played a role of simplifying the calculation, and the simplified seismic wave generated by blasting vibration can better simulate the influence of repeated blasting vibration on slope stability through sine wave with different loading times and amplitude. Therefore, the sine wave frequency in the test was $50 \mathrm{~Hz}$, that is to say, when the vibration times of shaking table was $1 \mathrm{~s}$ with $50 \mathrm{~Hz}$, it was equivalent to 50 times seismic waves generated by blasting vibration. In this paper, the load times of applied vibration consisted of 12 levels, including 7500 times, 1500 times, 2250 times, 3000 times, 3750 times, 4500 times, 5250 times, 6000 times, 7500 times, 9000 times, 11500 times and 12000 times. And loading amplitude consisted of 4 levels, including $0.5 \mathrm{~cm} / \mathrm{s}$, $0.9 \mathrm{~cm} / \mathrm{s}, 1.5 \mathrm{~cm} / \mathrm{s}$ and $2.2 \mathrm{~cm} / \mathrm{s}$, there were four levels of fault thickness, including $2 \mathrm{~cm}, 3 \mathrm{~cm}, 4 \mathrm{~cm}$, and $5 \mathrm{~cm}$. According to the paper of Basha and Babu [22], for the slope stability, the horizontal vibration played an absolute role, so the type of sine wave loaded in the test was the horizontal $\mathrm{X}$ direction. In order to obtain the cohesion force and internal friction angle values of similar materials in the fault fracture zone after each set of loading tests, under the action of a sine wave with different loading times and amplitudes, the test block made of similar materials in fault zone should be subjected to at least four levels of normal stress, and the corresponding peak shear stress should be recorded. Therefore, each test group was loaded with four test blocks of the same vibration characteristics, and the test model was loaded with normal stresses of $50 \mathrm{KPa}, 100 \mathrm{KPa}, 150 \mathrm{KPa}$, and $200 \mathrm{KPa}$. The model test system was shown in Fig. 4.

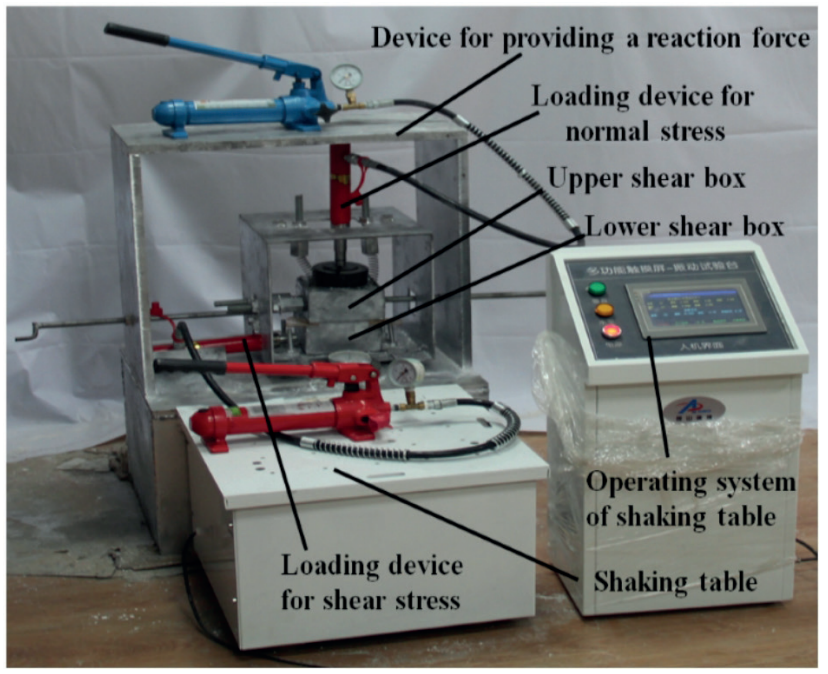

Fig. 4 System diagram of model test
In Fig. 4, the operating system of the shaking table had built-in software that had been strictly debugged, which can control the shaking table accurately and can also set up stable vibration waves with different frequency, amplitude, and time for vibration loading. And the shaking table and the middle part of a device for providing a reaction force were parallel, what's more, taking into account the existing test conditions and monitoring methods, shear test in this paper used the stress-controlled shear meter to monitor and record the parameters of the test model, and loading devices for shear stress and normal stress were controlled and recorded by someone, at the same time, the normal stress was kept constant, and the shear stress was applied step by step until the test specimen was cut off. And there were three cases showed that the fault zone has been destroyed by the shear load. The first case was that the shear load cannot be added or cannot reach stability, or the shear displacement was obviously increased; The second case was that the curve of the relationship between shear stress and shear displacement appeared abrupt section; The third case was that the increase of shear displacement did not appear obvious abrupt section in the curve of shear stress and shear displacement, while when the total shear displacement reached $10 \%$ of the side length of the test piece, it was also considered that the shear failure occurred in the test piece. Among them, the shear stress of each stage can be taken as $2 \%-5 \%$ of normal stress. After the test model passed the shaking table loading test, the fixed connection between the test device and the shaking table was removed, and the shaking table test device with the ball mounted on the lower part was slowly moved to the test shearing device which was consistent with the plane of the shaking table. The normal stress and shear stress in the shear test were applied by the jack, and then the change of the shear strength parameter of the fault fracture zone was analyzed by the change of the shear stress under different normal stress conditions.

\subsection{Test process}

The shaking table test procedure was as follows: the test model frame was installed on the vibrating table $\rightarrow$ the test model was assembled $\rightarrow$ the vertical surrounding rock stress device for loading model in X direction was installed, the horizontal surrounding rock stress device for loading model in $\mathrm{Z}$ direction was installed $\rightarrow$ the test model was loaded with different parameter variables sine wave $\rightarrow$ the test block model was subjected to a shear test $\rightarrow$ the stress and strain data was recorded during the shear test. The part process of the shaking table test was shown in Fig. 5. 

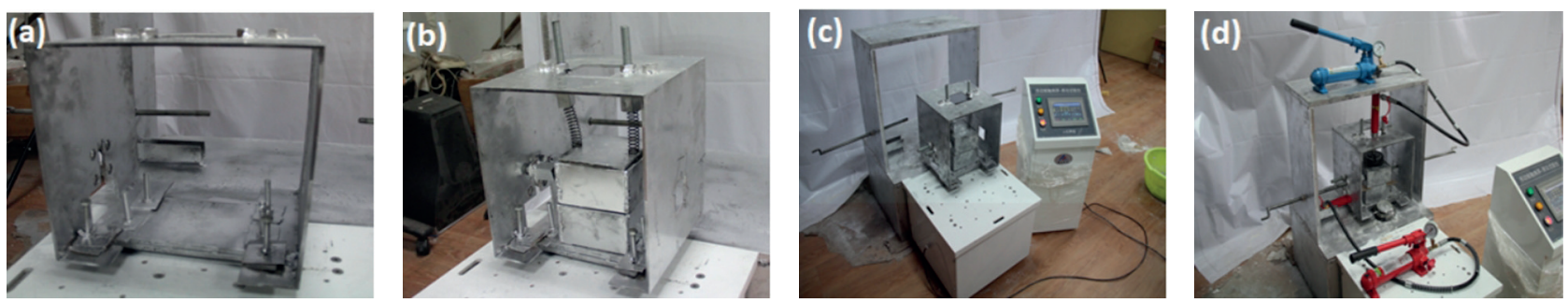

Fig. 5 Process of shear table test, (a) Test model starts install, (b) Test framework was installed, (c) The test model is loaded, (d) Shear test is carried out to with sine wave

\section{Analysis of test results}

\subsection{Shear strength parameters of the fault zone- loading time analysis}

During the test, the change of the shear strength of the fracture zone was obtained by calculation, and the calculation process was based on the Mohr-Coulomb failure theory. The change of the cohesion force and internal friction angle of the fracture zone with the loading times and loading amplitude was shown in Fig. 6. The relationship among cohesion force, internal friction angle, and blasting vibration loading times of the fault zone under different vibration characteristics was fitted, whose fitting results were shown in Table 3 and Table 4.

In Fig. 6, Table 3, and Table 4, under different blasting loading conditions, the shear strength parameters of the fault zone decreased with the increase of blasting vibration loading times, and the functional relation between them was in a form of the quadratic function. What's more, the weakening feature had the following two forms:

(1) When the loading amplitude was less than or equal to $1.5 \mathrm{~cm} / \mathrm{s}$, the shear strength parameter of the fault zone was mainly and gradually attenuating in this form. According to the loading times, the friction angle and cohesion force of the fault zone can be roughly divided into three stages: The first stage was the $A B_{1}$ stage, the $A B_{2}$ stage, and the $A B_{3}$ stage. The shear strength parameters of the fault zone decreased slowly and linearly with the increase of the loading times. In this stage, the elastic portion of the fracture zone partially recovered with the unloading of the sine wave, but the plastic or irreversible deformation was leftover. The second stage was the $B_{1} C_{1}$ stage, the $B_{2} C_{2}$ stage, and the $B_{3} C_{3}$ stage. The shear strength of the fault zone was getting smaller and smaller with the increase of loading times. This stage was the accelerated weakening stage of the fault zone. In this stage, the elastic deformation had completely disappeared in the fault zone, and new cracks were created and spread, which caused the mechanical properties of the fault zone to deteriorate further. The third stage was the $C_{1} D_{1}$ stage, $C_{2} D_{2}$ stage and, $C_{3} D_{3}$ stage in
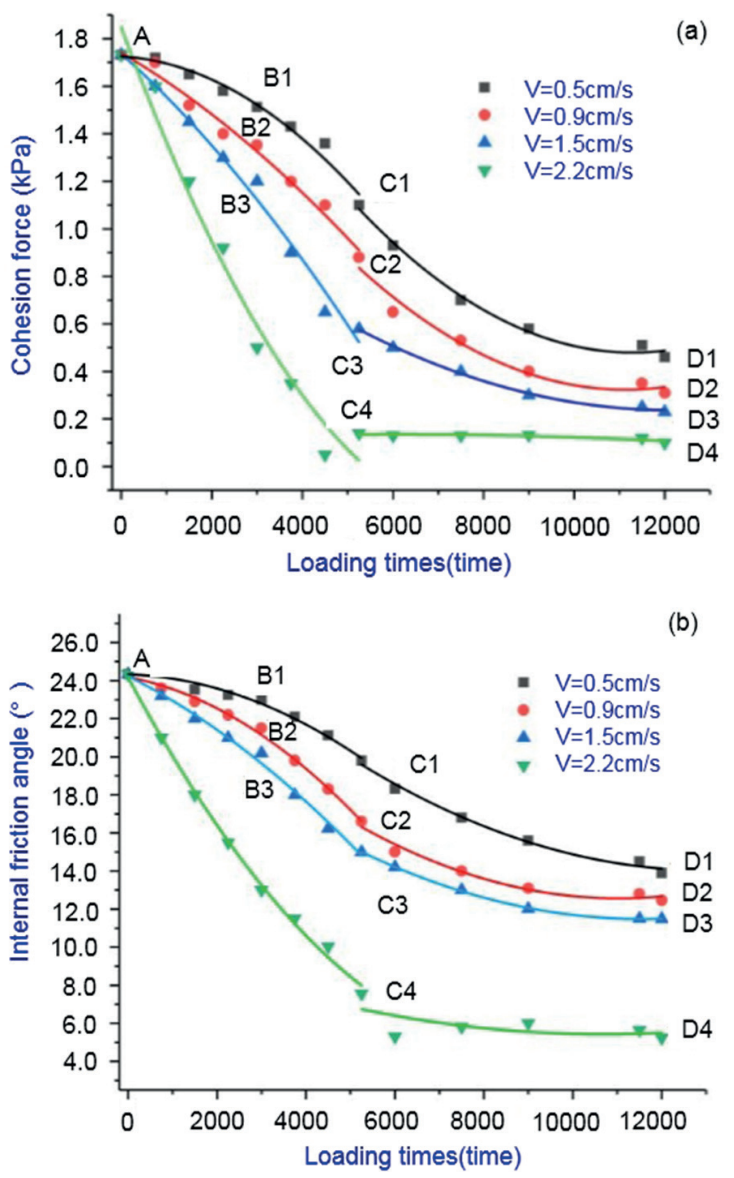

Fig. 6 Change of shear strength parameters of similar materials in the fault zone, (a) Cohesion force, (b) Internal friction angle

Fig. 6. In this stage, the plastic zone of the fault zone was connected. This stage was the failure stage of the fault zone. The shear strength parameters of the fault zone changed slowly with the increase of the loading time. At the same time, the fault zone had been completely destroyed under loading times, and the strength parameters of which no longer changed significantly.

(2) When loading amplitude was $2.2 \mathrm{~cm} / \mathrm{s}$, the damage of the fault zone was mainly in the form of inertial force failure, whose weakening performance was based primarily on additional loads. Compared with the first case, in this form, the weakening process of the fault zone had only two 
Table 3 Fitting results for relationship between cohesion force and blasting vibration loading time

\begin{tabular}{|c|c|c|c|c|c|c|c|c|}
\hline \multirow{2}{*}{$\begin{array}{l}\text { Loading } \\
\text { amplitude / } \\
(\mathrm{cm} / \mathrm{s})\end{array}$} & \multicolumn{8}{|c|}{ Load times/time } \\
\hline & $A$ & $B_{1}$ & $B_{2}$ & $R^{2}$ & $A$ & $B_{1}$ & $B_{2}$ & $R^{2}$ \\
\hline 0.5 & 218.59 & $2.1 \mathrm{E}-3$ & $-3 E-6$ & 0.98 & 306.3 & $-4.2 \mathrm{E}-2$ & $2.0 \mathrm{E}-6$ & 0.98 \\
\hline 0.9 & 222 & $-1.1 \mathrm{E}-2$ & $-2 \mathrm{E}-6$ & 0.98 & 201.5 & $-2.6 \mathrm{E}-2$ & $1.0 \mathrm{E}-6$ & 0.98 \\
\hline 1.5 & 235.1 & $-3.3 \mathrm{E}-2$ & $5 \mathrm{E}-7$ & 0.98 & 160.8 & $-2.1 \mathrm{E}-2$ & $9.0 \mathrm{E}-7$ & 0.98 \\
\hline 2.2 & 278.11 & $-9.6 \mathrm{E}-2$ & $9 E-6$ & 0.98 & 4.42 & $3.3 \mathrm{E}-3$ & $-2.0 \mathrm{E}-7$ & 0.98 \\
\hline
\end{tabular}

Table 4 Fitting results for the relationship between the internal friction angle and blasting vibration loading time

\begin{tabular}{|c|c|c|c|c|c|c|c|c|}
\hline \multirow{3}{*}{$\begin{array}{l}\text { Loading } \\
\text { amplitude / } \\
(\mathrm{cm} / \mathrm{s})\end{array}$} & \multicolumn{8}{|c|}{ Load times/time } \\
\hline & \multicolumn{4}{|c|}{$0-6000$} & \multicolumn{4}{|c|}{$6000-12000$} \\
\hline & $A$ & $B_{1}$ & $B_{2}$ & $R^{2}$ & $A$ & $B_{1}$ & $B_{2}$ & $R^{2}$ \\
\hline 0.5 & 24.28 & $-3 E-6$ & $-2 \mathrm{E}-7$ & 0.92 & 26.82 & -1.8 E-3 & $6 \mathrm{E}-8$ & 1.0 \\
\hline 0.9 & 24.22 & $-5 E-4$ & $-2 \mathrm{E}-7$ & 0.93 & 22.36 & $-1.6 \mathrm{E}-3$ & $7.1 \mathrm{E}-8$ & 1.0 \\
\hline 1.5 & 24.40 & -1.5 E-3 & $-5 \mathrm{E}-8$ & 0.92 & 23.41 & $-2.1 \mathrm{E}-3$ & $9.0 \mathrm{E}-8$ & 1.0 \\
\hline 2.2 & 24.00 & -4 E-3 & $2 \mathrm{E}-7$ & 0.91 & -0.51 & $1.4 \mathrm{E}-3$ & $-8.2 \mathrm{E}-8$ & 1.0 \\
\hline
\end{tabular}

stages. The initial stage was the $A C_{4}$ stage in Fig. 6. With the increase of loading time, the shear strength parameter of the fault zone failed rapidly. The fault zone was immediately destroyed after vibration loading at this stage. Then the second stage was the $C_{4} D_{4}$ stage in Fig. 6. At this stage, the shear strength parameter of the fault zone did not vary significantly with the increase of the loading times.

In Table $3, R^{2}$ represents the correlation coefficient, the fitting formula is $Y=A+B^{1} \times X+B^{2} \times Y^{2}, Y$ is cohesion force $X$ is the loading times, and $A, B^{1}, B^{2}$ are fitting parameters of the fitting formula.

In Table $4, R^{2}$ represents the correlation coefficient, the fitting formula is $Y=A+B^{1} \times X+B^{2} \times Y^{2}, Y$ is the internal friction angle $X$ is the times of loadings, and $A, B^{1}, B^{2}$ are fitting parameters of the fitting formula.

\subsection{Shear strength parameters of the fault zone- thickness of fault zone analysis}

Under the same blasting vibration loading amplitude and different loading times, the shear strength parameters of the fault fracture zone with different thicknesses were analyzed. And then the change of shear strength parameters with the loading time was shown in Fig. 7. The fitting results of the relationship among the internal friction angle and cohesion force of the fault fracture zone and the blasting vibration loading time were shown in Table 5.

It can be seen from Fig. 7 that under different blasting vibration loading time, the shear strength parameters of the fault fracture zone decreased with the decrease of the
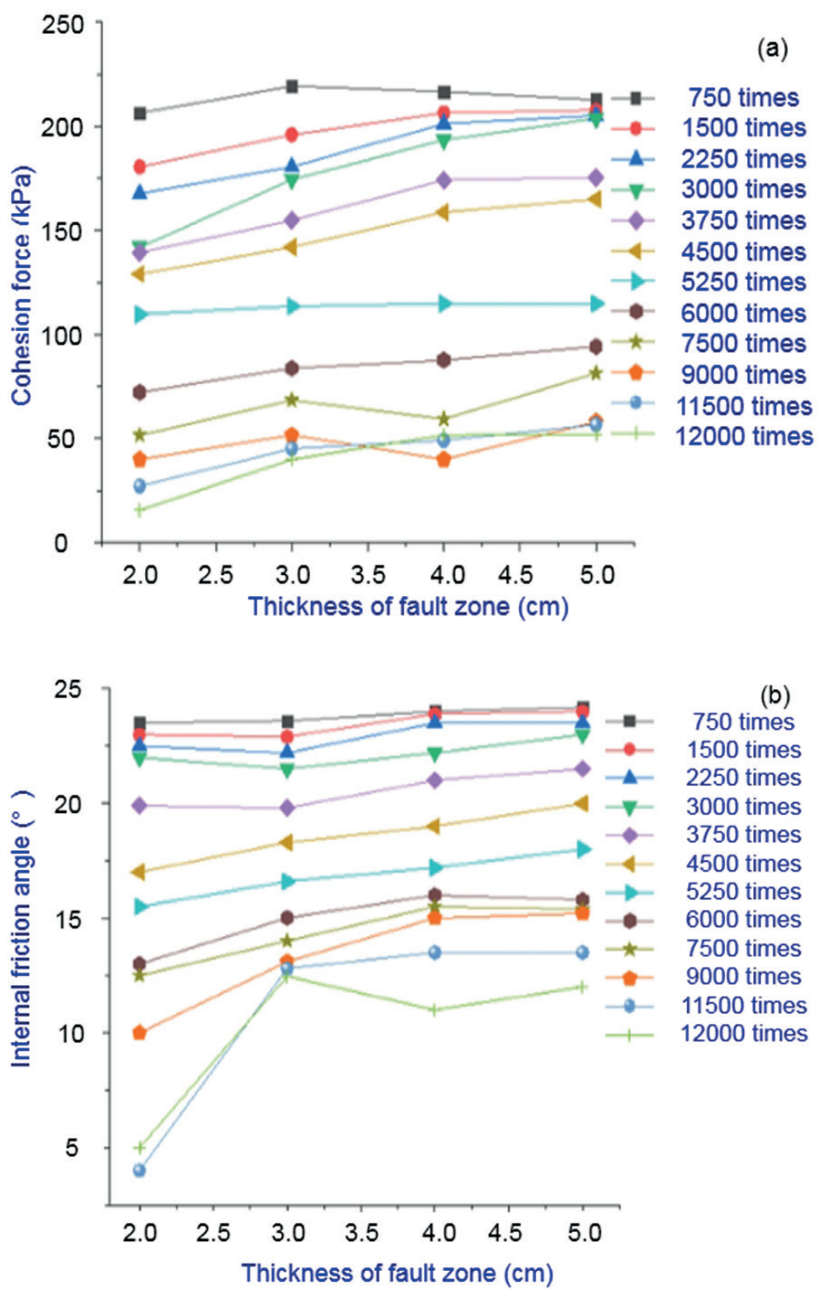

Fig. 7 Change of shear strength parameters of similar materials in the fault zone, (a) Cohesion force, (b) Internal friction angle 
Table 5 Fitting results for the relationship between the internal friction angle, the cohesion force in fault fracture zone and the thickness of the fault zone

\begin{tabular}{lcccccc}
\hline $\begin{array}{l}\text { Load } \\
\text { times/time }\end{array}$ & \multicolumn{2}{c}{ Cohesion force } & \multicolumn{5}{c}{ Internal friction angle } & $R^{2}$ \\
\hline 750 & 207.9 & 1.61 & 0.45 & 22.95 & 0.25 & 0.95 \\
1500 & 165.6 & 9.16 & 0.89 & 22.05 & 0.4 & 0.79 \\
2250 & 142.2 & 13.30 & 0.95 & 21.42 & 0.43 & 0.76 \\
3000 & 106.7 & 20.49 & 0.94 & 20.88 & 0.37 & 0.59 \\
3750 & 116.2 & 12.78 & 0.91 & 18.45 & 0.6 & 0.86 \\
4500 & 104.9 & 12.51 & 0.97 & 15.18 & 0.97 & 0.98 \\
5250 & 107.33 & 1.68 & 0.79 & 13.99 & 0.81 & 0.98 \\
6000 & 60.11 & 6.96 & 0.95 & 11.67 & 0.94 & 0.78 \\
7500 & 37.15 & 7.99 & 0.67 & 10.78 & 1.02 & 0.87 \\
9000 & 32.508 & 4.26 & 0.38 & 7.19 & 1.75 & 0.88 \\
11500 & 11.99 & 9.29 & 0.78 & 0.73 & 2.92 & 0.65 \\
12000 & -2.53 & 12.07 & 0.65 & 3.28 & 1.95 & 0.53 \\
\hline
\end{tabular}

thickness of the fault zone. At the same time, the relationship between the shear strength parameter and the thickness of the fault zone was in a form of the linear attenuation. The fitting results were shown in Table 5. It can be seen from Table 5 that as the thickness of the fault increased, the rate of attenuation of the cohesion force of the fault increased first and then decreased. When the loading time for the fault material was 3000 times, the slope of the cohesive force curve was 20.49 , which indicated that the cohesion force of the fault material was the strongest sensitivity to the thickness of the fault zone, at this time, the shear strength of the fault fracture zone was mainly attenuated by the cohesion force. When the loading time of the fault material was 11500 times, the slope of the internal friction angle curve was 2.92 , which indicated that the internal friction angle of the fault material was the strongest to the thickness of the fault zone. Meanwhile, the shear strength of the fault fracture zone was mainly decreased by the internal friction angle.

Where $R^{2}$ represents the correlation coefficient, the fitting formula is $Y=A+B \times X, Y$ is cohesion force or the internal friction angle, $X$ is the thickness of the fault zone, and $A, B$ are fitting parameters.

\section{Establishment of shear damage model of fault fracture zone}

Damage theory is often used to study the damage model of rock and soil. At the same time, with the assumption of Lemaitre strain equivalence [25], most of the commonly used damage models are established as shown in Eq. (1).
$\tau_{1}=\tau_{1}^{\prime}(1-D)$

where: $\tau_{1}$ is nominal shearing stress; $\tau_{1}^{\prime}$ is the effective shear stress; $D$ is the percentage of damage. The model shows that the main reason for the damage of rock and soil is the formation of cavities inside. That is to say, the rock under load can be abstracted into two parts: undamaged material and cavities, and the cavities do not have any shear resistance. Therefore, when the rock is completely damaged (i.e. $D=1$ ), the nominal shear stress of rock and soil, which is $\tau_{1}$, must be 0 , that is, the residual strength is 0 , which is obviously contrary to the reality. For this reason, Shah and Ribakov [26] abstracted the rock and soil materials after loading into two parts: damaged and undamaged materials, and the stress of the rock and soil materials was jointly borne by these two parts of materials, so a new damage model of the rock and soil materials was proposed. It is shown in Eq. (2).

$\tau_{1}=\tau_{1}^{\prime}(1-D)+\tau^{\prime \prime} D$

where: $\tau_{1}^{\prime \prime}$ is the shear stress of the damaged part of the material, and the meaning of other physical quantities is the same as that of the previous model. The model shows that the rock and soil materials still have a certain bearing capacity after damage, which is obviously reasonable. When the rock and soil materials are incomplete damage state (i.e. $D=1), \tau_{1}=\tau^{\prime \prime}$ land $\tau_{1}=\tau^{\prime} 1(1-D)=0$. It can be seen from the above formula that the rock and soil materials in the state of complete damage still have the certain bearing capacity, therefore, in order to further explore the damage model of rock and soil materials and establish a more reasonable damage model, the following assumptions are made at first:

(1) The rock and soil materials under vibration loading are composed of numerous microelements uniformly, which can be abstracted as two parts of undamaged and damaged materials in the axial direction. The axial stress is borne by both parts of the materials. As shown in Fig. 8, the blank part is the undamaged part of materials, and the shadow part is the damaged part of the materials [27-28].

(2) Under the limit stress state, the stress state $\left(\sigma_{1}\right.$ and $\left.\sigma_{3}\right)$ and rock strength parameters (normal stress $\sigma$ and shear stress $\tau$ ) of some undamaged rock and soil materials meet the Coulomb strength criterion, which is shown in Eq. (3) and Eq. (4).

$\tau^{\prime}=\frac{1}{2}\left(\sigma_{1}^{\prime}-\sigma_{3}^{\prime}\right) \sin 2 \theta$, 
$\sigma^{\prime}=\frac{1}{2}\left(\sigma_{1}^{\prime}+\sigma_{3}^{\prime}\right)+\frac{1}{2}\left(\sigma_{1}^{\prime}-\sigma_{3}^{\prime}\right) \cos 2 \theta$,

where: $\sigma^{\prime}$ is the effective normal stress of the structural plane, $\tau^{\prime}$ is the effective shear stress of the structural plane. $\theta$ is the internal friction angle of the structural plane, $\sigma_{1}{ }^{\prime}$ is the effective first principal stress of the structural plane. $\sigma_{3}$ ' is the effective third principal stress of the structural plane.

(3) The damage of rock only occurs in the horizontal shear direction, and no damage occurs in the lateral direction, that is to say, the load of rock and soil material in the horizontal direction is borne by the damaged and undamaged parts of materials, while the nominal normal stress of rock in the vertical direction is equal to the effective normal stress. The shear stress of rock and soil material in the horizontal direction is borne by the damaged and undamaged materials, while the nominal normal stress $\sigma$ and effective normal stress $\sigma^{\prime}$ of rock in the vertical direction are equal.

(4) The damage of rock means that the rock material is destroyed, and the horizontal shear stress of the damaged rock material reaches the residual strength rapidly, that is to say, the horizontal shear stress of the damaged rock material is the residual stress strength $\tau_{1}^{r}$.

According to the above assumptions, an improved damage model of rock and soil materials can be established. The specific process is as follows: firstly, the microelement of rock is selected for analysis.

As shown in Fig. 9, the macro nominal horizontal shear stress of the microelement is assumed to be $\tau_{1}$, the micro horizontal shear stress of the rock and soil material in the undamaged part is $\tau_{1}^{\prime}$, the micro horizontal shear stress of the rock and soil material in the damaged part is $\tau_{1}^{r}$, and the cross-sectional area of the micro element is $A$, where the cross-sectional areas of the undamaged and damaged parts are $A_{1}$ and $A_{2}$ respectively. Obviously, Eq. (5) and Eq. (6) can be obtained from Eq. (1) in this paper.

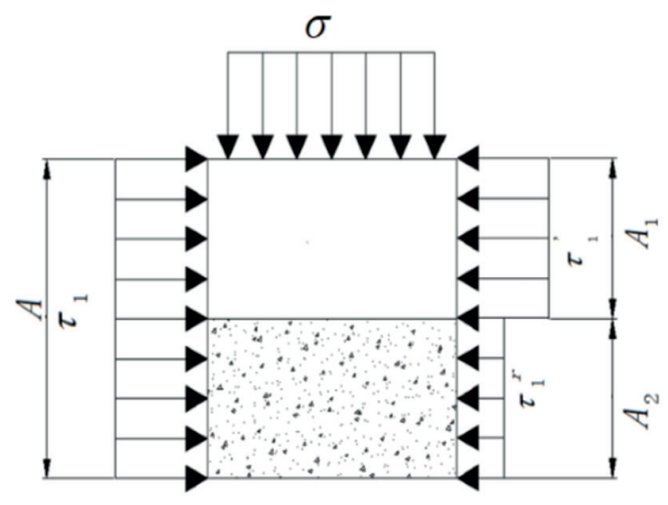

Fig. 8 Analysis of micro horizontal stress of rock element

$$
\begin{aligned}
& \tau_{1} A=\tau_{1}^{\prime} A_{1}+\tau_{1}^{r} A_{2} \\
& A=A_{1}+A_{2}
\end{aligned}
$$

If it is defined as $D=A_{2} / A_{1}$, that is to say, the horizontal damage variable or damage factor of rock and soil can be obtained from Eq. (5) and Eq. (6), which is shown in Eq. (7).

$\tau_{1}=\tau_{1}^{\prime}(1-D)+\tau_{1}^{r} D$

Eq. (7) is a new damage model of rock and soil materials. From this equation, it can be seen that when the rock is in the state of complete damage $(D=1), \tau_{1}=\tau_{1}^{r}$ can be obtained, and $\tau_{1}^{r}$ is the horizontal residual shear strength of rock, which does not change with the increase of deformation. Obviously, the damage model established in this paper can reflect the deformation process characteristics of the residual strength deformation stage of rock and soil materials, which is better than the two damage models mentioned above. In order to establish a constitutive model that can reflect the degradation law of shear strength of rock and soil materials, the residual strength $\tau_{1}^{r}$ and damage variable $D$ need to be determined.

\subsection{Establishment of a new damage constitutive model applied to fault fracture zone}

Since fault materials are composed of damaged and undamaged materials, which are closely mixed with each other, according to the assumption (3) and the principle of deformation coordination, the Eq. (8) can be obtained.

$\sigma^{\prime}=\sigma$

Therefore, Eq. (9) can be obtained by Eq. (4) and Eq. (8).

$\sigma=\frac{1}{2}\left(\sigma_{1}^{\prime}+\sigma_{3}^{\prime}\right)+\frac{1}{2}\left(\sigma_{1}^{\prime}-\sigma_{3}^{\prime}\right) \cos 2 \theta$

In addition, since $\tau_{1}^{r}$ is the horizontal residual shear strength of the fault fracture zone, i.e. the axial residual strength of the fault fracture zone, which follows MohrCoulomb criterion [15], so we can obtain Eq. (10).

$\sigma_{1}^{r}=\frac{\left(1+\sin \theta_{r}\right) \sigma_{3}^{r}+2 C_{r} \cos \theta_{r}}{1-\sin \theta_{r}}$

where: $C_{r}$ and $\theta_{r}$ are respectively the residual cohesion and residual friction angle of the fault fracture zone. Because the rock and soil materials in the damaged part also meet the Coulomb strength criterion between the ultimate stress state (principal stress $\sigma_{1}$ and $\sigma_{3}$ ) and the rock strength parameters (normal stress $\sigma$ and shear stress $\tau$ ), so we can obtain Eq. (11). 
$\tau_{1}^{r}=\frac{1}{2}\left(\sigma_{1}^{r}-\sigma_{3}^{r}\right) \sin 2 \theta_{r}$

Therefore, Eq. (12) can be obtained by Eq. (11) and Eq. (10):

$\tau_{1}^{r}=\frac{1}{2} \frac{2 \sin \theta_{r} \sigma_{3}^{r}+2 C_{r} \cos \theta_{r}}{1-\sin \theta_{r}} \sin \theta_{r}$

The relationship between the normal force on the shear plane and the shear force on the shear plane of the undamaged part of the fault material obeys Mohr-Coulomb criterion, which is shown in Eq. (13).

$\tau_{1}^{\prime}=\sigma \tan \theta+C$,

where: $C$ and $\theta$ are the peak cohesion and friction angle of the fault material in the shear test. Therefore, Eq. (12) and Eq. (13) can be substituted into Eq. (7) to obtain Eq. (14).

$\tau_{1}=(\sigma \tan \theta+C)(1-D)+B_{1} D$,

where,

$B_{1}=\frac{1}{2} \frac{2 \sin \theta_{r} \sigma_{3}^{r}+2 C_{r} \cos \theta_{r}}{1-\sin \theta_{r}} \sin \theta_{r}$.

Equation (14) is the damage model of fault material under the shear test condition. The damage constitutive model of fault material established by this formula still needs to solve the problem of determining the damage variable or damage factor $D$.

\subsection{The establishment of the model of fault damage evolution}

In this paper, the statistical damage theory is proposed to establish the fault damage evolution model. It is a widely used method to establish the rock damage evolution model [29]. The key is the reasonable measurement of the microelement strength of rock. For this reason, a method of measuring the microelement strength of rock is established by introducing the idea of Eberhardt [30], which can be expressed as follows Eq. (16).

$F=\sigma_{1}^{\prime}+\beta \sigma_{3}^{\prime}+\gamma$,

where: $F$ is microelement strength of fault materials. $\beta$ and $\gamma$ are constants related to cohesion $C$ and internal friction angle $\theta$ at the peak value of rock mass material, specifically expressed as follows Eq. (17) and Eq. (18).

$\beta=\frac{1+\sin \theta}{\sin \theta-1}$ $\gamma=\frac{2 C \cos \theta}{\sin \theta-1}$

Combining Eq. (8) with Eq. (9) and Eq. (16), Eq. (19) is obtained.

$F=\frac{2 \sigma-\sigma_{3}^{\prime}(1-\cos 2 \theta)}{1+\cos 2 \theta}+\beta \sigma_{3}^{\prime}+\gamma$

Equation (19) is the method to measure the strength of fault microelements. The damage of fault materials is caused by the continuous development of microelements, assuming that the failure probability of fault materials is $P\left[f\left(\sigma^{\prime}\right)\right]$, and the damage variable $D$ can be defined as Eq. (20).

$D=\int_{0}^{f\left(\sigma^{\prime}\right)} P\left[f\left(\sigma^{\prime}\right)\right] d x$

In this paper, the statistical damage evolution model of fault material can be established by assuming that the microelement strength of fault material obeys Weibull distribution and considering the influence of damage threshold [31-32]. If the microelement strength of the fractured material obeys the Weibull distribution, the microelement size can be considered to contain enough micro pores and cracks, or it can be considered as the concept of a particle in continuum mechanics, and its probability density function is expressed as shown in Eq. (21).

$$
P(F)=\frac{m}{F_{0}}\left(\frac{F}{F_{0}}\right)^{m-1} \exp \left[-\left(\frac{F}{F_{0}}\right)^{m}\right]
$$

In the Eq. (21), $m$ and $F_{0}$ are Weibull distribution parameters of microelement strength $(F)$ of fault materials. If the influence of the damage threshold is considered, Eq. (22) can be obtained by Eq. (20) and Eq. (21), which represents the statistical damage evolution model of fault materials.

$D= \begin{cases}1-\exp \left[-\left(F / F_{0}\right)^{m}\right] & F>0 \\ 0 & F \leq 0\end{cases}$

Therefore, combining Eq. (22) and Eq. (14), a statistical damage constitutive model can be obtained under the shear test conditions, which is used to simulate the gradual decline of shear strength of fault materials.

\subsection{Determination of parameters of damage constitutive model for fault materials}

Combining Eq. (22) and Eq. (14), the attenuation statistical damage constitutive model of shear strength of fault materials under shear test can be obtained. It can be seen that the determination of the model parameters $m$ and $F_{0}$ is one of the key problems in the model establishment. The 
constitutive model parameters can be established according to the extreme value characteristics of the normal stress shear stress curve of the degradation of the shear strength of rock and soil materials. The specific analysis process is as follows. If the normal stress shear stress curve under different normal stress is at the peak point, the corresponding normal stress and shear stress are $\sigma_{S C}$ and $\tau_{S C}$ respectively, then Eq. (23) can be obtained.

$$
\left.\frac{\partial \tau}{\partial \sigma}\right|_{\tau=\tau_{S C}, \sigma=\sigma_{S C}}=0
$$

Equation (24) can be obtained by partial differential solution of Eq. (14).

$$
\frac{\partial \tau}{\partial \sigma}=\tan \theta-D \tan \theta+\left(B_{1}-C-\sigma \tan \theta\right) \frac{\partial D}{\partial \sigma}
$$

Therefore, Eq. (25) can be obtained by combining Eq. (23) and Eq. (24).

$$
\left.\frac{\partial D}{\partial \sigma}\right|_{\tau=\tau_{S C}, \sigma=\sigma_{S C}}=\frac{\left(D_{S C}-1\right) \tan \theta}{\left(B_{1}-C-\sigma_{S C} \tan \theta\right)}
$$

Where, when $\tau=\tau_{S C}$ and $\sigma=\sigma_{S C}, D_{S C}$ is determined as damage variable $D$ by Eq. (22), Eq. (26) can be obtained by partial differential solution of Eq. (22).

$$
\frac{\partial D}{\partial \sigma}=\exp \left[-\left(\frac{F}{F_{0}}\right)^{m}\right]\left[m\left(\frac{F_{s c}}{F_{0}}\right)^{m-1}\right] \frac{1}{F_{0}} \frac{\partial F}{\partial \sigma}
$$

Equation (27) can be solved by partial differentiation of Eq. (19).

$$
\frac{\partial F}{\partial \sigma}=\frac{2}{1+\cos 2 \theta}
$$

Equation (28) and Eq. (29) can be obtained by combining Eq. (27) and Eq. (22).

$$
\begin{aligned}
& \exp \left[-\left(\frac{F}{F_{0}}\right)^{m}\right]=1-D \\
& \left(\frac{F}{F_{0}}\right)^{m-1}=-\frac{F}{F_{0}} \ln (1-D)
\end{aligned}
$$

Equation (30) can be obtained by combining Eq. (25) to Eq. (29).

$$
m=\frac{F_{s c} \tan \theta(1+\cos 2 \theta)}{2\left(B_{1}-C-\sigma_{S C} \tan \theta\right) \ln \left(1-D_{S C}\right)},
$$

where: When $\sigma=\sigma_{\mathrm{SC}}$ and $\tau=\tau_{S C}$, the microelement strength $F$ of fault material is $F_{S C}$, which is determined by Eq. (19).

$$
F_{s c}=\frac{2 \sigma_{S C}-\sigma_{3}^{\prime}(1-\cos 2 \theta)}{1+\cos 2 \theta}+\beta \sigma_{3}^{\prime}+\gamma
$$

Combining $D=D_{S C}$ and $\sigma=\sigma_{S C}$ and Eq. (28), Eq. (32) can be obtained.

$$
F_{0}=F_{s c}\left[-\ln \left(1-D_{S C}\right)\right]^{-1 / m}
$$

Combining $\sigma=\sigma_{S C}$ and $\tau=\tau_{S C}$ and Eq. (14), Eq. (33) can be obtained.

$D_{S C}=\frac{\tau_{S C}-\left(\sigma_{S C} \tan \theta+C\right)}{B_{1}-\left(\sigma_{S C} \tan \theta+C\right)}$

In order to establish a unified constitutive model that can simulate the shear strength degradation of fault materials under different confining pressures and different loading times, the constitutive model parameters $m$ and $F_{0}$ needs to be determined, among which the constitutive model parameters $m$ and $F_{0}$ can be determined according to Eq. (28) and Eq. (30). However, these two parameters contain peak stress $\tau_{S C}$ under specific confining pressure, and the value of peak stress $\tau_{S C}$ is different for different confining pressure, so in order to obtain the degradation constitutive model of shear strength of fault materials, the determination method of peak stress should be given.

\subsection{Example and verification of shear cumulative damage model for fault materials}

In order to verify the rationality of the theoretical model, the degradation constitutive model of shear strength of

\begin{tabular}{|c|c|c|c|c|c|c|c|c|c|c|c|c|}
\hline Loading amplitude/(cm/s) & & 0.5 & & & 0.9 & & & 1.5 & & & 2.2 & \\
\hline Normal stress & 100 & 200 & 300 & 100 & 200 & 300 & 100 & 200 & 300 & 100 & 200 & 300 \\
\hline$\tau_{S C}$ & 6.30 & 26.00 & 42.00 & 8.00 & 19.50 & 37.00 & 7.00 & 14.00 & 32.00 & 6.80 & 13.00 & 28.00 \\
\hline$m$ & -0.21 & -0.92 & -1.08 & -0.76 & -1.05 & -0.10 & -0.65 & -0.94 & -0.58 & -0.76 & -0.76 & -0.42 \\
\hline$F_{0}$ & 1.58 & 19.26 & 40.81 & 5.87 & 18.32 & 33.35 & 3.74 & 12.15 & 18.58 & 4.61 & 8.04 & 11.92 \\
\hline
\end{tabular}
fault materials with the change of loading times and loading amplitude can be obtained by combining the peak cohesion and friction angle data under different loading amplitude and loading times, which was shown in Table 3 and Table 4. Table 6 showed the parameter values of the theoretical prediction model of cumulative shear damage under different normal stress and loading amplitude. The comparison between the measured value of shear stress of

Table 6 Parameter Values of cumulative shear damage model of fault materials under different normal stress and loading amplitude 

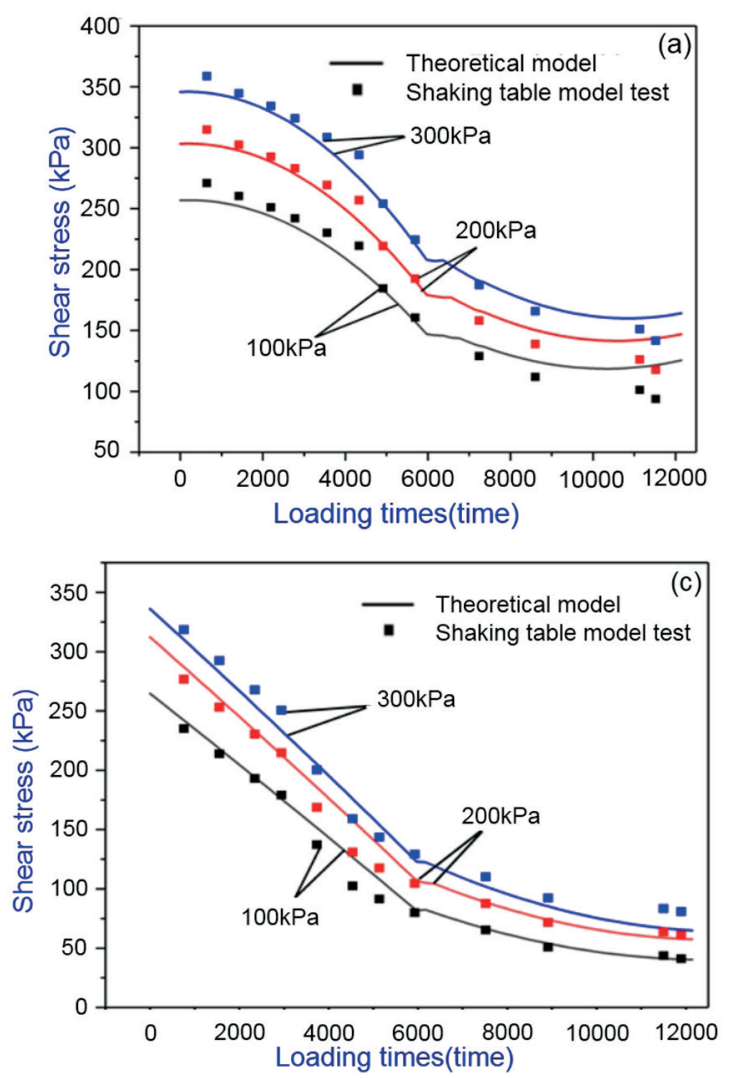
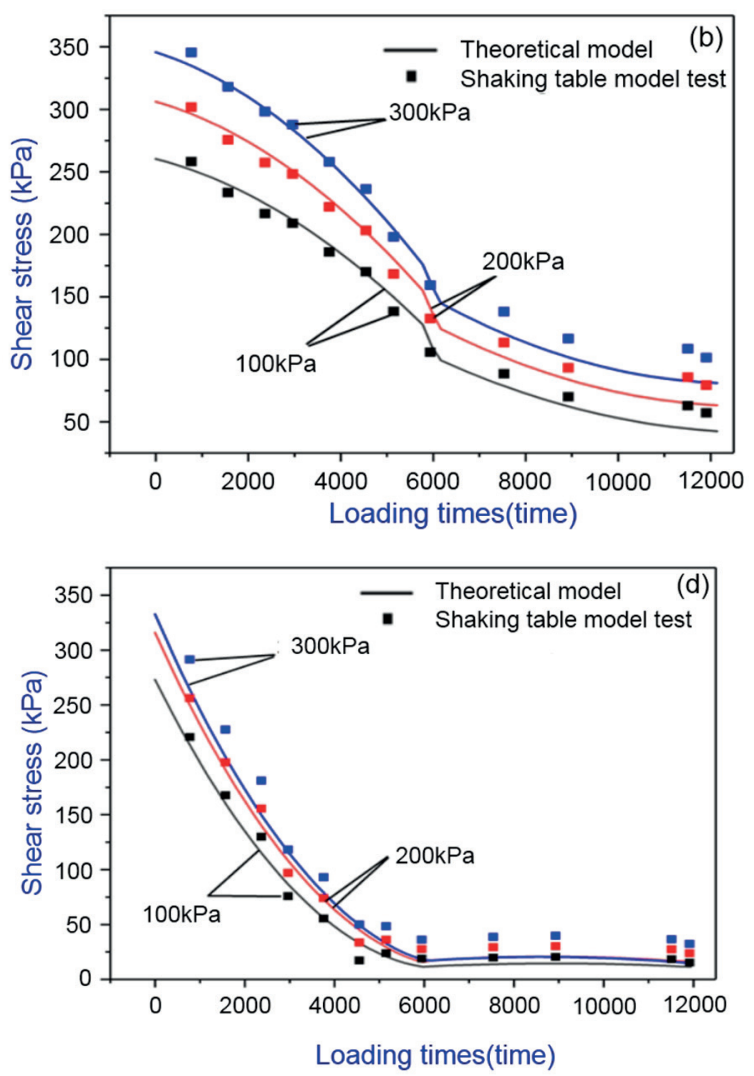

Fig. 9 Comparison between the test value of shear stress and the predicted value of theoretical model, (a) $0.5 \mathrm{~cm} / \mathrm{s},(\mathrm{b}) 0.9 \mathrm{~cm} / \mathrm{s},(\mathrm{c}) 1.5 \mathrm{~cm} / \mathrm{s},(\mathrm{d}) 2.2 \mathrm{~cm} / \mathrm{s}$

fault fracture zone by shaking table model tests and the predicted value of the theoretical model under different normal stress and loading amplitude was shown in Fig. 9.

It can be seen from Fig. 9 that under the same loading amplitude, the shear stress of fault fracture zone increased with the increase of normal stress, and with the increase of loading amplitude, the influence of different normal stress on the magnitude of shear stress gradually decreased, which showed that when the normal stress was larger and the buried depth of fault fracture zone was larger, the shear strength of fault fracture zone was higher, and the influence of loading amplitude on its magnitude was weaker.

At the same time, the shear stress value of the fault fracture zone gradually decreased with the increase of loading times and loading amplitude, and when the loading amplitude was small, it can be seen that the curve showed three obvious stages of change, that is, first slow decreased, then accelerate decreased, and finally tended to balance. However, with the increase of the loading amplitude, the three-stage change of the curve gradually changed to twostage change, which showed that the loading amplitude has an obvious effect on the degradation of the shear strength of the fault fracture zone, which can reduce the elastic part of the fault fracture zone in the process of deformation, and directly make the fault fracture zone enter the elastic-plastic or even damage stage.

By comparing the test data with the theoretical curve, it can be seen that the fitting between the test results and the theoretical results was good. The predicted results of the theoretical model can reflect the attenuation trend of the fault fracture zone with the loading amplitude, normal stress, and loading times. It showed that the damage constitutive model considering the residual stress intensity of horizontal shear stress can fully reflect the attenuation change of the fault fracture zone, which was consistent with the change of blasting parameters.

According to the concept of rock yield, the parameters of the shear stress prediction model in fault fracture zone were determined by the extreme value method, which was suitable for the solution of loading test data under different loading amplitudes and confining pressure. It does not contain unconventional rock mechanical parameters, so it is more convenient for engineering applications. In the process of establishing the mechanical parameters damage model of fault fracture zone, the mechanical parameters and statistical distribution parameters used in the model are independent of lithology, so the model is also suitable for other rocks with different lithology. 


\section{Conclusions}

We investigated the cumulative damage process and change of fault fracture zone with different thicknesses under repeated blasting vibration loads with different loading amplitudes and different loading times. Based on what we have discussed above, the following conclusions are drawn:

1. Under different blasting conditions, the shear strength parameters of the fault zone decreased with the increase of blasting vibration loading time, and the functional relation between them was a quadratic function. When the loading amplitude was less than or equal to $1.5 \mathrm{~cm} / \mathrm{s}$, the degradation form of the shear strength parameter of the fault zone was mainly in the form of cumulative weakening. And when the loading amplitude was $2.2 \mathrm{~cm} / \mathrm{s}$, the damage of the fault zone was mainly in the form of inertial force failure, whose weakening performance was primarily based on additional loads.

2. Under the action of different blasting vibration loading time, the shear strength parameters of the fault fracture zone decreased with the decrease of the thickness of the fault zone. At the same time, the relationship between the shear strength parameter and the loading amplitude accorded with the linear attenuation. The influence of the loading amplitude on the degradation of the shear strength parameters of the fault material increased first and then decreased. When the loading time was the 3000 times, the cohesive force of the fault was the most sensitive to the thickness of the fault zone. When the loading time was 11500 times, the internal friction angle of the fault was the most sensitive to the thickness of the fault zone.

\section{References}

[1] Holden, R. J., Bahls, D., Real, C. "Estimating economic losses in the Bay Area from a magnitude-6.9 earthquake", Monthly Labor Review, 130(12), pp. 16-22, 2007. [online] Available at: https:// www.bls.gov/opub/mlr/2007/12/art2full.pdf

[2] Take, W. A., Bolton, M. D., Wong, P. C. P., Yeung, F. J. "Evaluation of landslide triggering mechanisms in model fill slopes", Landslides, 1, pp. 173-184, 2004.

https://doi.org/10.1007/s10346-004-0025-1

[3] Mein, R. G., Larson, C. L. "Modeling infiltration during a steady rain", Water Resources Research, 9(2), pp. 384-394, 1973.

https://doi.org/10.1029/WR009i002p00384

[4] Buocz, I., Rozgonyi-Boissinot, N., Török, Á. "Influence of Discontinuity Inclination on the Shear Strength of Mont Terri Opalinus Claystones", Periodica Polytechnica Civil Engineering, 61(3), pp. 447-453, 2017.

https://doi.org/10.3311/PPci.10017
3. By comparing the test data with the theoretical curve, it can be seen that the fitting between the test results and the theoretical results was good. The predicted results of the theoretical model can reflect the attenuation trend of the fault fracture zone with the loading amplitude, normal stress, and loading times. According to the concept of rock yield, the parameters of the shear stress prediction model in fault fracture zone were determined by the extreme value method, which was suitable for the solution of loading test data under different loading amplitudes and confining pressure. Meanwhile, the damage prediction model in this paper did not contain nonconventional rock mechanical parameters, so it is more conservative for engineering application, on the other hand, the cumulative effect of micro-vibration was considered in the statistical model, which can better reflect the influence of cumulative dynamic load on the statistical damage constitutive model of rock and soil. Therefore, the research in this paper should be more applied to the stability evaluation of soft rock slope or high and steep mine slope with the soft structural surface.

\section{Acknowledgement}

This research was funded by the National Natural Science Foundation of China (NSFC, Grant no. 41972286, Grant no. 41372312, Grant no. 41807265), and the Natural Science Foundation of Hubei Province of China (NSFH, Grant no. 2017CFB310), and the Fundamental Research Funds for the Central Universities, China University of Geosciences (Wuhan) (CUG, Grant no. CUGQY1931). The finical support from NSFC, NSFH and CUG is gratefully acknowledged.

[5] Sanchez, G., Rolland, Y., Corsini, M., Braucher, R., Bourlès, D., Arnold, M., Aumaître, G. "Relationships between tectonics, slope instability and climate change: Cosmic ray exposure dating of active faults, landslides and glacial surfaces in the SW Alps", Geomorphology, 117(1-2), pp. 1-13, 2010. https://doi.org/10.1016/j.geomorph.2009.10.019

[6] Matsuura, S., Asano, S., Okamoto, T. "Relationship between rain and/or meltwater, pore-water pressure and displacement of a reactivated landslide", Engineering Geology, 101(1-2), pp. 49-59, 2008. https://doi.org/10.1016/j.enggeo.2008.03.007

[7] Montrasio, L., Valentino, R., Losi, G. L. "Rainfall-induced shallow landslides: a model for the triggering mechanism of some case studies in Northern Italy", Landslides, 6, pp. 241-251, 2009. https://doi.org/10.1007/s10346-009-0154-7

[8] Sorbino, G., Nicotera, M. V. "Unsaturated soil mechanics in rainfall-induced flow slide", Engineering Geology, 165, pp. 105-132, 2013.

https://doi.org/10.1016/j.enggeo.2012.10.008 
[9] Esmaeili-Falak, M., Katebi, H., Javadi, A. "Experimental Study of the Mechanical Behavior of Frozen Soils - A Case Study of Tabriz Subway", Periodica Polytechnica Civil Engineering, 62(1), pp.117125, 2017. https://doi.org/10.3311/PPci.10960

[10] Schnellmann, R., Busslinger, M., Schneider, H. R., Rahardjo, H. "Effect of rising water table in an unsaturated slope", Engineering Geology, 114(1-2), pp. 71-83, 2010. https://doi.org/10.1016/j.enggeo.2010.04.005

[11] Saada, Z., Maghous, S., Garnier, D. "Stability analysis of rock slopes subjected to seepage forces using the modified Hoek- Brown criterion", International Journal of Rock Mechanics and Mining Sciences, 55, pp. 45-54, 2012. https://doi.org/10.1016/j.ijrmms.2012.06.010

[12] Cho, S. E. "Probabilistic stability analysis of rainfall-induced landslides considering spatial variability of permeability", Engineering Geology, 171, pp. 11-20, 2013. https://doi.org/10.1016/j.enggeo.2013.12.015

[13] Kritikos, T., Robinson, T. R., Davies, T. R. H. "Regional coseismic landslide hazard assessment without historical landslide inventories: A new approach", Journal of Geophysical Research Earth Surface, 120(4), pp. 711-729, 2015. https://doi.org/10.1002/2014jf003224

[14] Nishimura, T. "Slip distribution of the 1973 Numuro-oki earthquake estimated from the re-examined geodetic data", Earth Planets Space, 61, pp. 1203-1214, 2009. https://doi.org/10.1186/BF03352973

[15] Zarroca, M., Linares, R., Roqué, C., Rosell, J., Gutiérrez, F. "Integrated geophysical and morphostratigraphic approach to investigate a coseismic (?) translational slide responsible for the destruction of the Montclús village (Spanish Pyrenees)", Landslides, 11, pp. 655-671, 2014. https://doi.org/10.1007/s10346-013-0427-z

[16] Asadollahi, P., Tonon, F. "Degradation of rock fracture asperities in unloading, reloading, and reversal", International Journal for Numerical and Analytical Methods in Geomechanics, 35(12), pp. 1334-1346, 2011. https://doi.org/10.1002/nag.960

[17] Xiao, J.-Q., Ding, D.-X., Jiang, F.-L., Xu, G. "Fatigue damage variable and evolution of rock subjected to cyclic loading", International Journal of Rock Mechanics and Mining Sciences, 47(3), pp. 461$468,2010$.

https://doi.org/10.1016/j.jirmms.2009.11.003

[18] Jiang, N., Zhou, C., Lu, S., Zhang, Z. "Effect of Underground Mine Blast Vibrations on Overlaying Open Pit Slopes: A Case Study for Daye Iron Mine in China", Geotechnical and Geological Engineering, 36, pp.1475-1489, 2018. https://doi.org/10.1007/s10706-017-0402-x

[19] Koo, R. C. H., Kwan, J. S. H., Sze, E. H. Y. "Stability assessment of soil slopes subject to blasting vibrations based on time history analyses", HKIE Transactions, 23(3), pp. 130-137, 2016. https://doi.org/10.1080/1023697X.2016.1201438
[20] Meehan, C. L., Brandon, T. L., Duncan, J. M., Tiwari, B. "Direct shear testing of polished slickensided surfaces", Landslides, 7, pp. $157-167,2010$. https://doi.org/10.1007/s10346-010-0199-7

[21] Kimura, S., Nakamura, S., Vithana, S. B., Sakai, K. "Shearing rate effect on residual strength of landslide soils in the slow rate range", Landslides, 11, pp. 969-979, 2014. https://doi.org/10.1007/s10346-013-0457-6

[22] Basha, B. M., Babu, G. L. S. "Reliability assessment of internal stability of reinforced soil structures: A pseudo-dynamic approach", Soil Dynamics and Earthquake Engineering, 30(5), pp. 336-353, 2010.

https://doi.org/10.1016/j.soildyn.2009.12.007

[23] He, J. Y., Zhang, S. X. "Blast vibration influences on slope during transformation of surface mining to underground mining", Mining and Metallurgy Engineering, 26(5), pp. 1-5, 2006. (in Chinese)

[24] Zhang, S., Hu, J., Yang, S. "Monitoring and analysis of blast vibration in underground engineering", Blasting, 2001(02), pp. 49-52, 2001. (in Chinese)

[25] Lemaitre, J. "How to use damage mechanics", Nuclear Engineering and Design, 80(2), pp. 233-245, 1984. https://doi.org/10.1016/0029-5493(84)90169-9

[26] Shah, A. A., Ribakov, Y. "Non-destructive evaluation of concrete in damaged and undamaged states", Materials \& Design, 30(9), pp. 3504-3511, 2009. https://doi.org/10.1016/j.matdes.2009.03.008

[27] Peng, J., Rong, G., Cai, M., Yao, M., Zhou, C. "Comparison of mechanical properties of undamaged and thermal-damaged coarse marbles under triaxial compression", International Journal of Rock Mechanics and Mining Sciences, 83, pp. 135-139, 2016. https://doi.org/10.1016/j.ijrmms.2015.12.016

[28] Wen, T., Tang, H., Ma, J., Liu, Y. "Energy Analysis of the Deformation and Failure Process of Sandstone and Damage Constitutive Model", KSCE Journal of Civil Engineering, 23, pp. 513-524, 2019. https://doi.org/10.1007/s12205-018-0789-9

[29] Resende, L., Martin, J. B. "Parameter identification in a damage model for rock mechanics", International Journal for Numerical and Analytical Methods in Geomechanics, 12(1), pp. 79-97, 2010. https://doi.org/10.1002/nag.1610120106

[30] Eberhardt, E. "Numerical modelling of three-dimension stress rotation ahead of an advancing tunnel face", International Journal of Rock Mechanics and Mining Sciences, 38(4), pp. 499-518, 2001. https://doi.org/10.1016/S1365-1609(01)00017-X

[31] Sivapragash, M., Lakshminarayanan, P. R., Karthikeyan, R., Raghukandan, K., Hanumantha, M. "Fatigue life prediction of ZE41A magnesium alloy using Weibull distribution", Materials \& Design, 29(8), pp. 1549-1553, 2008. https://doi.org/10.1016/j.matdes.2008.01.001

[32] Basu, B., Tiwari, D., Kundu, D., Prasad, R. "Is Weibull distribution the most appropriate statistical strength distribution for brittle materials?", Ceramics International, 35(1), pp. 237-246, 2009. https://doi.org/10.1016/j.ceramint.2007.10.003 